\title{
Virtual Minimization of Residual Stress and Deflection Error in the Five-Axis Milling of Turbine Blades
}

\author{
Mohsen Soori* - Mohammed Asmael \\ Eastern Mediterranean University, Department of Mechanical Engineering, Turkey
}

To simulate and analyse the real machined parts in virtual environments, virtual machining systems are applied to the production processes. Due to friction, chip forming, and the heat produced in the cutting zone, parts produced using machining operation have residual stress effects. The machining force and machining temperature can cause the deflection error in the machined turbine blades, which should be minimized to increase the accuracy of machined blades. To minimize the residual stress and deflection error of machined parts, optimized machining parameters can be obtained. In the present research work, the application of a virtual machining system is presented to predict and minimize the residual stress and deflection error in a five-axis milling operations of turbine blades. In order to predict the residual stress and deflection error in machined turbine blades, finite element analysis is implemented. Moreover, to minimize the residual stress and deflection error in machined turbine blades, optimized parameters of machining operations are obtained by using a genetic algorithm. To validate the research work, experimentally determining residual stress by using a X-ray diffraction method from the machined turbine blades is compared with the finite element results obtained from the virtual machining system. Also, in order to obtain the deflection error, the machined blades are measured by using the CMM machines. Thus, the accuracy and reliability of machined turbine blades can be increased by analysing and minimizing the residual stress and deflection error in virtual environments.

Keywords: virtual machining, residual stress, deflection error, parameter optimization, turbine blade

\section{Highlights}

- The application of a virtual machining system is presented to predict and minimize the residual stress and deflection error in the five-axis milling operations of turbine blades.

- In order to minimize the residual stress and deflection error in machined turbine blades, an optimization technique based on genetic algorithms is used.

- The accuracy and reliability of machined turbine blades can be increased by analysing and minimizing the residual stress and deflection error in virtual environments.

\section{INTRODUCTION}

The residual stress in machined parts can be generated as a result of mechanical, thermal, and chemical effects in chip forming of metal cutting operations. The generated residual stress in the machined parts can impair the performance of components, such as fatigue life, corrosion resistance, and part distortion in actual working conditions. Due to the cutting forces and cutting temperature, the machined blades have deflection errors, which can cause inaccuracy in the machined turbine blades. As a result, the residual stress and deflection error should be analysed and decreased to increase the accuracy and reliability of parts produced using machining operations.

To improve the precision of machined parts, the evaluation of surface error characteristics in thin-walled constructs during peripheral milling has been studied by Wimmer and Zaeh [1]. The process parameter optimization of thin-wall machining for wire arc additive manufactured parts is investigated by Grossi et al. [2] to decrease the deformation error in the thin-walled manufactured components. The method of error compensation during the milling operations of flexible thin-wall parts is presented by Ratchev et al. [3] to reduce the deflection error of machined parts. To improve the accuracy of thin-walled machined parts, an adaptive toolpath methodology for three-axis milling is presented by Grossi et al. [4]. The finite element method (FEM) based cutting velocity selection for thin-walled part machining is presented by Scippa et el. [5] to enhance the precision of machined components. Finite-Element modelling of workpiece vibrations is analysed by Bolsunovskiy et al. [6] to optimize the machining parameters and increase accuracy in the milling operations of thinwalled components.

Jiang et al. [7] analysed the effects of cutting forces and cutting zone temperature to the residual stress of machined components. The application of response surface methodology in obtaining the optimized machining parameters, such as depth of cut and spindle speed, are investigated by Masmiati et al. [8] in order to minimize the residual stress, cutting force, and surface roughness in the end milling of S50C medium carbon steel. Mohammadpour et al. [9] investigate the effects of machining parameters on the residual stress of machined parts in milling 
operations. To analyse the influence of the machining parameters, such as cutting speed as well as feed rate, on the surface roughness and residual stresses in produced parts using milling operation, the finite element method is used by Zhang and $\mathrm{Wu}[10]$.

To decrease the residual stress in machined parts using turning operations, the effects of cutting tool parameters, such as tool nose radius and tool wear on residual stresses, are investigated by Lin et al. [11]. Cutting tool parameters, such as tool edge radius, are investigated by Yang et al. [12] in order to decrease the residual stress in machined parts. To study the effects of cutting-edge radius and cutting forces on residual stresses of machined parts, a finite element model is developed by Nasr et al. [13].

To decrease the residual stress in machined parts and effects of cutting tools materials, machining parameters, such as cutting speeds and depth of cut to residual stress of machined parts, are investigated by Arunachalam et al. [14]. The influence of cutting tool parameters, such as tool nose radius on surface integrity and residual stresses, are investigated by Sharman et al. [15] to decrease the residual stress in machined parts. A variable depth-of-cut milling strategy for thin-walled workpiece is proposed by Yan et al. [16] in order to decrease the deflection error in the machined turbine blades. A five-axis adaptive flank milling of flexible thin-walled parts based on the on-machine measurement is developed by Huang et al. [17] to modify the cutting tool paths in terms of deflection error minimization. The time domain flutter analysis based on the blade element momentum (BEM) theory for bend-twist coupled large composite wind turbine blades is investigated by Shakya et al. [18] to increase the performances of wind turbines in actual working conditions. The blisk vibration in aircraft engine using similitude models is analysed by Luo et al. [19] to predict and decrease the vibration of the engine systems in the virtual environments. To analyse and modify the machining operations in virtual environments, virtual machining systems and applications are presented by Soori et al. [20] to [24]. To analyse and develop the process of part manufacturing using welding operations, a review in recent development of friction stir welding process is presented by Soori et al. [25]. To increase efficiency in process of part production using the friction stir spot welding, effects of machining parameters to the mechanical properties of aluminium sheet alloys is presented by Nasir et al. [26].

According to the analysis of previous published papers, the area of residual stress as well as deflection error prediction and minimization in milling operations by using virtual machining systems has been insufficiently explored. Moreover, to minimize the residual stress and deflection errors in machined parts, the applications of the virtual machining system is not studied.

In this research work, the application of a virtual machining system is presented to predict and minimize the residual stress and deflection error in a five-axis milling operations of turbine blades. The cutting forces as well as cutting temperatures for each position of cutting tool along machining paths are calculated in order to obtain residual stress and deflection error of blades due to machining operations by using the finite element analysis (FEA). The optimization technique of a genetic algorithm is used to calculate the optimized machining parameters in terms of residual stress and deflection error minimization. To measure the residual stresses on the surface and in-depth of the machined blades, the X-ray diffraction technique is used in the study. The coordinate measuring machines (CMM) machines are sued to obtain the deflection error in the machined blades. Finally, the obtained data are compared by using diagrams.

\section{CUTTING FORCE MODEL}

To calculate the cutting forces in the five-axis machining operations, the cutting force model developed by Zhang et al. [27] is applied.

The $X Y Z$ planes are defined in order to describe the tool motion process, workpiece geometry and tool path in machining operations. Also, $X_{r} Y_{r} Z_{r}$ is created in order to describe the tool rotation coordinate system in machining operations. Thus, the cutting forces in the differential format, which is applied to the $j^{\text {th }}$ axial disk element of the $i^{\text {th }}$ tooth at rotation angle $\phi_{i, j}(t)$, can be presented as:

$$
\left\{\begin{array}{l}
d F_{T, i, j}(t)=\left(K_{t s} h(i, j, t) d b+K_{t p} d b\right) W\left(\theta\left(\phi_{i, j}(t)\right)\right) \\
d F_{R, i, j}(t)=\left(K_{r s} h(i, j, t) d b+K_{r p} d b\right) W\left(\theta\left(\phi_{i, j}(t)\right)\right), \\
d F_{A, i, j}(t)=\left(K_{a s} h(i, j, t) d b+K_{a p} d b\right) W\left(\theta\left(\phi_{i, j}(t)\right)\right)
\end{array}\right.
$$

where $h(i, j, t)$ is the instantaneous uncut chip thickness of the $j^{\text {th }}$ axial disk element of the $i^{\text {th }}$ tooth at $t$ moment and the $d b$ is the axial height of the cutting disk element. Moreover, the coefficients of shearing specific cutting force in different directions as tangential, radial, and axial can be shown as:

$$
k_{q s}=a_{q s}+b_{q s} e^{c_{q s} h(t)}(q=t, r, a) .
$$


Also, the coefficients of ploughing specific cutting force in different directions as tangential, radial, and axial direction can be presented as:

$$
k_{q p}=a_{q p}+b_{q p} e^{c_{q p} h(t)}(q=t, r, a) .
$$

To determine whether the condition of disk element is in or out of cutting operation, the $W(\theta)$ can be presented as:

$$
w\left(\theta\left(\phi_{i, j}(t)\right)\right)=\left\{\begin{array}{ll}
1 & \theta_{s t, i, j} \leq \theta\left(\phi_{i, j}(t)\right) \leq \theta_{e x, i, j} \\
0 & \text { others }
\end{array},\right.
$$

where $\theta_{e x, i, j}$ stand for entry and exit angle of $j^{\text {th }}$ disk element on $i^{\text {th }}$ tooth respectively, as shown in Fig. 1 [27].

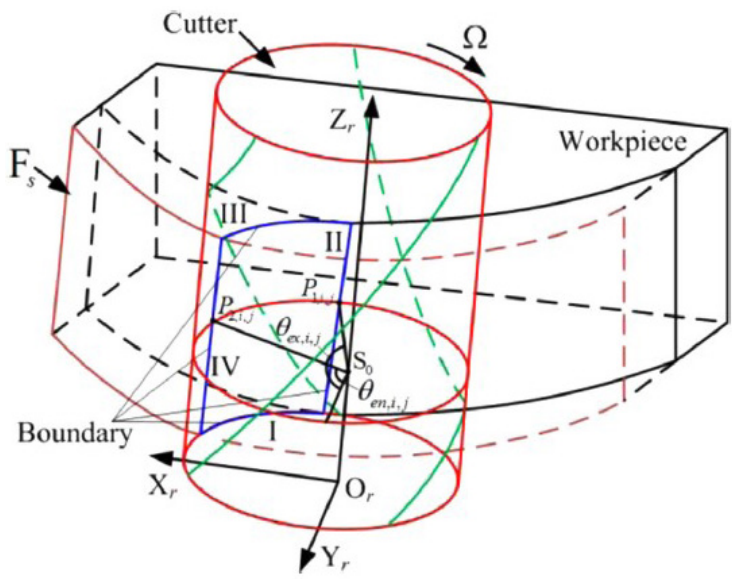

Fig. 1. Entry and exit angle model of cutting tool [27]

Thus, the overall cutting forces that are applied to the $t$ moment can be calculated by summing three cutting forces acting on disk element within axial depth of cut as is shown in Eq. (3).

$$
\left[\begin{array}{l}
F_{c, x}(t) \\
F_{c, y}(t) \\
F_{c, z}(t)
\end{array}\right]=\sum_{i} \sum_{j} \operatorname{Rot}\left[\begin{array}{l}
d F_{T, i, j}(t) \\
d F_{R, i, j}(t) \\
d F_{A, i, j}(t)
\end{array}\right],
$$

where Rot is the cutter rotation matrix. With the aid of transformation relationship matrix in the five-axis machine tool, the total cutting force components acting on the workpiece can be obtained by:

$$
\left[\begin{array}{c}
F_{w, x}(t) \\
F_{w, y}(t) \\
F_{w, z}(t)
\end{array}\right]=-\operatorname{Rot} C \cdot \operatorname{RotB}\left[\begin{array}{l}
F_{c, x}(t) \\
F_{c, y}(t) \\
F_{c, z}(t)
\end{array}\right],
$$

where $\operatorname{Rot} C \cdot \operatorname{Rot} B$ is rotation matrix for $B$-axis and $C$-axis.

\section{CUTTING TEMPERATURE MODEL}

In the machining operations, the chip formation process generates heat in the cutting zone. To model the cutting temperature regarding the cutting parameters, the response surface methodology (which is statistical) and mathematical techniques can be applied. The experimental values of cutting temperature corresponding to the control variables of machining parameters are incorporated into the response surface methodology in terms of cutting temperature model modification [28]. As a result, The equation of the cutting temperature regarding the cutting parameters based on response surface methodology is presented by Shaw [29] as,

$$
\lambda=C_{\lambda} V^{b 1} f_{z}^{b 2} a_{e}^{b 3} a_{p}^{b 4},
$$

where $\lambda$ is temperature $\left[{ }^{\circ} \mathrm{C}\right], C_{\lambda}$ is temperature coefficient determined by workpiece material, machine tool, and cutting tool geometry parameter. The $b_{1}, b_{2}, b_{3}$, and $b_{4}$ are exponents influencing the machining parameters $V$, cutting speed $(\mathrm{m} / \mathrm{min}), f_{z}$, feed rate (mm/rotation), $a_{e}$, radial feed [mm] and $a_{p}$, axial feed [mm].

To obtain the experimental values of cutting temperature and calculate the cutting temperature during machining operation, the tool-workpiece thermocouple device with three brushes is used. The electromotive force produced in the tool-workpiece thermocouple circuit during machining is proportional to the temperature difference between the tool and room temperature. Extruded round bars $(101 \mathrm{~mm}$ $\times 2000 \mathrm{~mm}$ ) of the aluminium alloys $1350-\mathrm{O}$ and 7075-T6 were used as the workpiece. The cutting tool used in the experiment is carbide bar $(310 \times 10 \times 4)$ $\mathrm{mm} \mathrm{K} 15$ grade, and the tool holder is $(25 \times 20 \times 150)$ $\mathrm{mm}$ made of steel. The cutting speed $600 \mathrm{~m} /$ minute, feed rate $0.3 \mathrm{~mm} /$ rotation and axial depth of cut $3 \mathrm{~mm}$ are considered as machining parameters of the experiments. The average of the chip-tool temperatures measured by the tool workpiece thermocouple system (average of two replicates) are calculated using analysis of variance of the $2^{k}$ factorial design as input variables. The coefficients of the temperature model are then calculated using a statistic analysis based on multiple nonlinear regression of the chip-tool interface temperature over 32 experiments. As a result, the equations of the cutting tool and workpiece temperatures in the machining operations of Al alloys based on multiple nonlinear regression analysis are presented by Santos et al. [30] as: 


$$
\begin{gathered}
\lambda_{t}=116.503 V^{0.211} f_{z}^{0.181} a_{e}^{0.0464} a_{p}^{0.00391}, \\
\lambda_{w}=43.319 V^{0.365} f_{z}^{0.244} a_{e}^{0.0423} a_{p}^{0.019},
\end{gathered}
$$

where $\lambda$ is temperature $\left[{ }^{\circ} \mathrm{C}\right], V$ is cutting speed $[\mathrm{m} /$ min], $f_{z}$ is feed rate [mm/rotation], $a_{e}$ and $a_{p}$ are radial feed and axial feed $[\mathrm{mm}]$, respectively.

\section{DEFLECTION ERROR ANALYSIS OF THIN-WALL WORKPIECE IN MACHINING OPERATIONS}

The machining operations of thin-walled parts have deflection errors as a result of cutting forces as well as cutting temperature. The workpiece deflects to a new position due to cutting forces and cutting temperatures which creates dimensional errors and inaccuracies in the process of machining operations.

The corresponding surface dimensional error can be presented as Eq. (8) [31],

$$
e_{p}=\delta_{t, p}+\delta_{f, p},
$$

where, $\delta_{t, p}$ and $\delta_{f, p}$ are the normal projections of the cutting force and cutting temperature-induced deflection error for the Point $\mathrm{P}$, respectively.

For the convenience of study, the distance between the initial surface to be machined and the desired machined surface is named as the nominal radial depth of cut notated by $R_{N}$. In the actual milling process, to ensure that the surface dimensional error does not violate the tolerance, $R_{A}$ is often specified to be different from $R_{N} \neq R_{A}$. In this case, Eq. (9) is no longer applicable to the calculation of surface dimensional error and must be corrected as [31]:

$$
e_{p}=\delta_{t, p}+\delta_{f, p}+R_{N}-R_{A} .
$$

Note that $R_{N}$ and $R_{A}$ are the nominal and specified radial depth of cut, respectively.

\section{VIRTUAL MACHINING SYSTEM}

The Visual Basic programming language is used in this study to develop the presented virtual machining system. The developed virtual machining system can obtain the cutting forces regarding the cutting tool details and parameters of machining operations. Thus, cutting forces at each position of the cutting tool along machining paths can be calculated.

The software calculates the cutting temperature regarding the cutting process parameters at each position of the cutting tool along machining paths. Then, the software is linked to the Abaqus R2016X FEM analysis software to analyse the residual stress and deflection error due to machining operations.
The calculated cutting forces and cutting temperature at each position of cutting tool along the machining paths in turbine blade machining are input to Abaqus software to be used for residual stress and deflection error calculations. As a result, the residual stress and deflection error due to cutting forces and cutting temperatures at each position of the cutting tool can be calculated and presented. A flowchart and the strategy of the virtual machining system in cutting force calculation, residual stress and deflection error prediction are shown in Fig. 2.

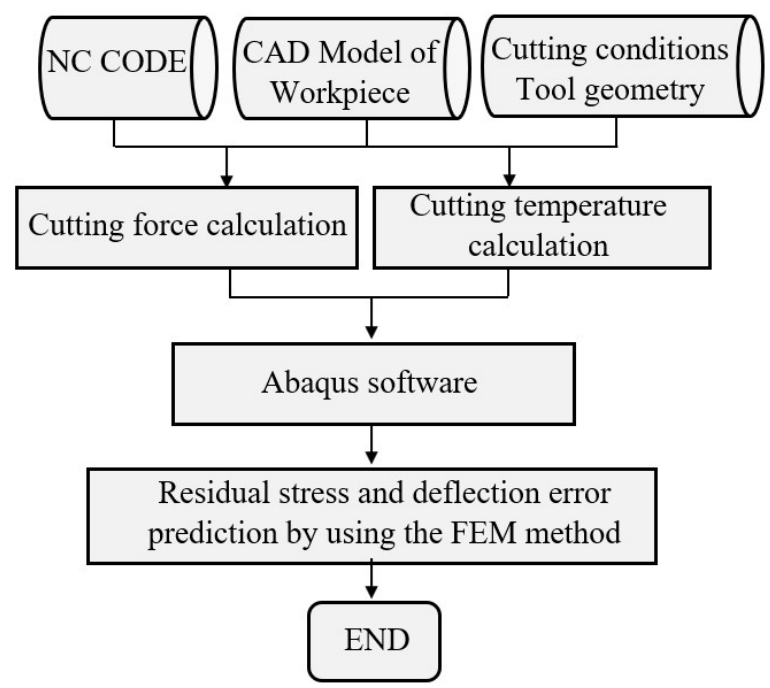

Fig. 2. Flowchart of the virtual machining system

To obtain the optimized machining parameters in terms of residual stress and deflection error minimizations, the genetic algorithm is applied. The genetic algorithm is an advanced optimization method based on natural selection by which the fittest individuals are selected for reproduction to produce offspring of the next generation. The natural process of evolution and set of chromosomes is introduced in terms of optimization process. The initial population for the optimization process is created using the binary encoding process. To provide evaluation criteria in the optimization process and rank the chromosomes in the population, the fitness function is calculated as is presented in Eq. (10) [32].

$$
F(x)=\frac{1}{1+f(x)},
$$

where fitness function and objective function are $F(x)$ and $f(x)$, respectively. The main operators of the algorithms are reproduction, crossover, and mutation. The operators are applied to the initial population of 
the optimization process in order to provide a faster convergence to the optimized parameters.

The mathematical equation of the surface roughness in end milling operations is presented in Eq. (11) [33].

$$
R_{a}=318 \frac{f^{2}}{4 d}
$$

where $f$ is the feed rate, and $d$ is the diameter of the cutting tool. Moreover, the time of machining operation should be minimized in order to decrease the cost of machined parts. The mathematical equation of machining time is presented in Eq. (12) [33].

$$
t_{m}=\frac{k}{f},
$$

where $k$ is the distance of cutting tool to reach to the operational zone and $f$ is feed rate.

Also, the cutting tool life should be maximized in the optimization process in order to decrease the cost of machining operation. The cutting tool life can be shown as Eq. (13) [33].

$$
T_{L}=\left(\frac{60}{Q}\right)\left[\frac{C\left(\frac{G}{5}\right)}{V(A)^{W}}\right]^{\frac{1}{m}},
$$

where $Q$ is the contact proportion of cutting edge with workpiece per revolution, $C$ is 33.98 for the highspeed steel (HSS) tools and 100.05 for the carbide tools, $g=0.14, V$ is cutting speed $[\mathrm{mm} / \mathrm{min}], w=0.28$, $m$ is 0.15 for HSS tools while it reaches a maximum of 0.30 for carbide tools, $G$ and $A$ are slenderness ratio and chip cross-section, which can be shown as Eqs. (14) and (15), respectively [33].

$$
\begin{gathered}
G=\frac{a}{f}, \\
A=a \cdot f,
\end{gathered}
$$

where $a$ is a depth of cut and $f$ is feed rate in machining operations.

According to Eqs. (6) and (7), the cutting temperature can be decreased by reducing the feed rate and spindle speed. Also, according to Eq. (11), the surface roughness can be decreased by reducing the feed rate. However, the machining time will be increased by reducing the feed rate according to Eq. (12). Moreover, increasing the spindle speed can decrease the cutting forces according to Eq. (4) and cutting tool life according to Eq. (13). It is clear that the presented mathematical models of the cutting forces, cutting temperature, time of machining operations, surface roughness, feed rate and cutting tool life are related, which should be considered as an optimization problem. The objective function of the optimization process is minimizing the residual stress and deflection error by calculating the optimized machining parameters. To obtain the optimized machining parameters in order to minimize the residual stress and deflection error using the minimized cutting forces and cutting temperature in machined turbine blade, the Matlab programming language is used. As a result, the optimized feed rate and spindle speed are obtained in order to minimize the residual stress as well as deflection error in the machined parts. The complete methodology of the study is shown in Fig. 3.

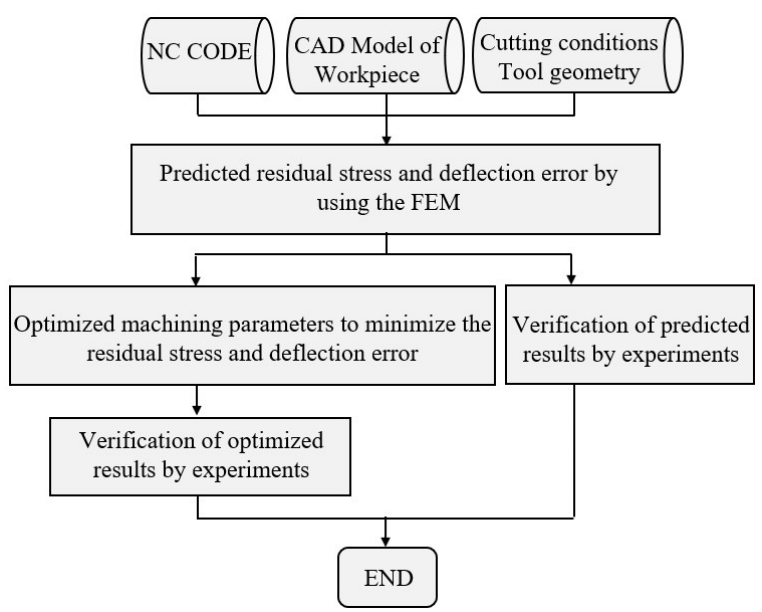

Fig. 3. Methodology of the study

\section{VALIDATION AND COMPARISON}

In order to validate the presented virtual machining system in the study, real turbine blades are machined by using the A 5-axis computer navigated control (CNC) milling machine tool Kondia HM 1060. The turbine blade material is AL 2618, which is used in the compressor section of gas turbines. Then, the test turbine blades are machined by using the five-axis Kondia HM $1060 \mathrm{CNC}$ machine tool. The cutting tool used in the experiment is a carbide flat end mill with $10 \mathrm{~mm}$ diameter, helix angle $30^{\circ}$, flute number 4, overall length $60 \mathrm{~mm}$ and flute length $30 \mathrm{~mm}$. The feed rate and spindle speed are $100 \mathrm{~mm} / \mathrm{min}$ and $1000 \mathrm{rpm}$, respectively. The machining process of the turbine blade is shown in Fig. 4.

To calculate the cutting forces in virtual environments, the cutting force model of five-axis 
CNC machine tools presented by Zhang et al. [27] is used in this study.

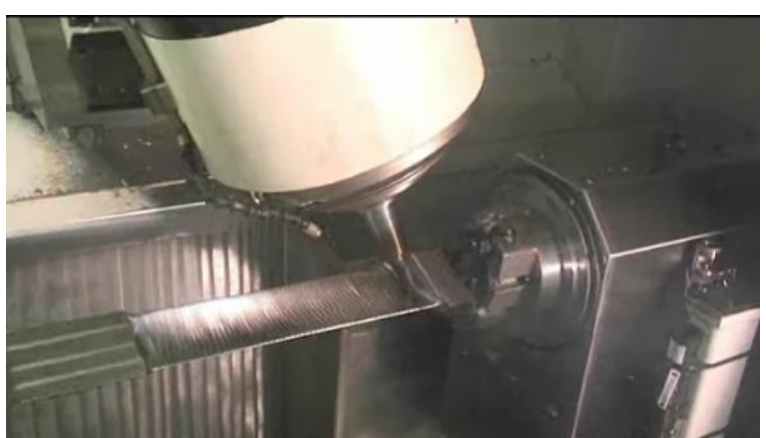

Fig. 4. Machining process of the turbine blades

In order to calculate the coefficients of specific cutting force, the average of cutting forces for twenty slot milling tests with $1.5 \mathrm{~mm}$ axial depth of cut using 5-axis CNC milling machine tool Kondia HM 1060 are measured with a Kistler dynamometer. The spindle rotating speed is $5000 \mathrm{rpm}$ and the feed per tooth and feed rate are $0.5 \mathrm{~mm}$ and $100 \mathrm{~mm} / \mathrm{min}$, respectively. The cutting tool overhang is $60 \mathrm{~mm}$. As result, the specific cutting force coefficients are obtained as Fig. 6.

The real machined Al turbine blades are shown in Fig. 5.

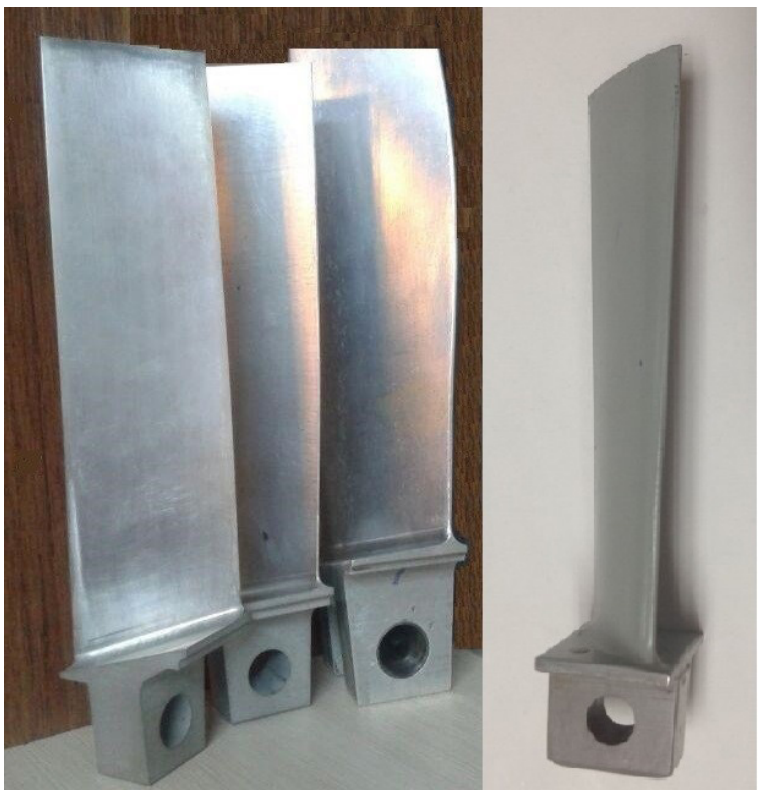

Fig. 5. The real machined turbine blades

The cutting forces and cutting temperatures for each position of the cutting tool along machining paths are obtained by using the virtual machining system. Then, the cutting forces and cutting temperatures are entered into Abaqus software to obtain the residual stress and deflection error of machined blades. Thus, the calculated residual stresses by Von Mises yield criterion due to machining operation of turbine blade in MPa unit are shown in Fig. 7.

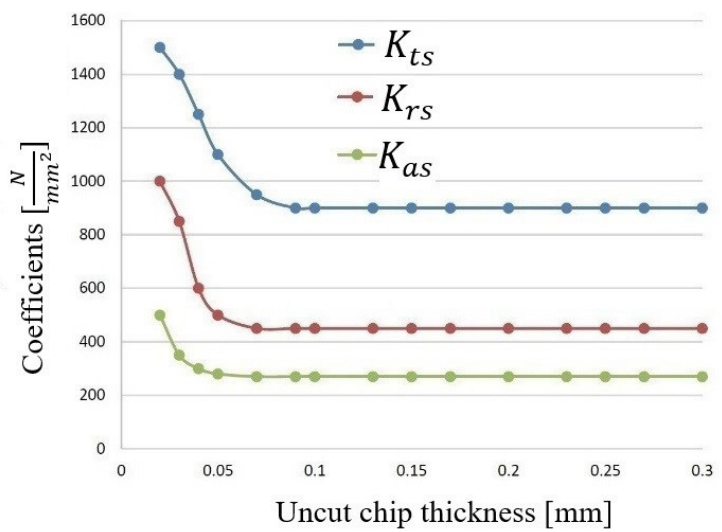

b)

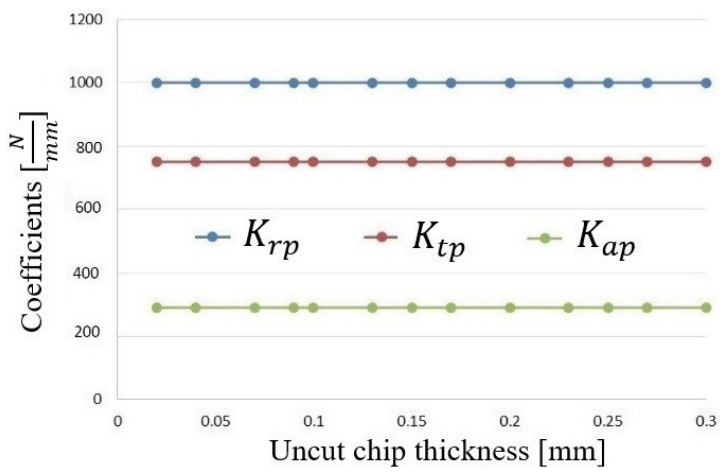

Fig. 6. Specific cutting force coefficients, a) $K_{t s}, K_{r s}, K_{a s}$, and b) $K_{r p}, K_{t p}, K_{a p}$

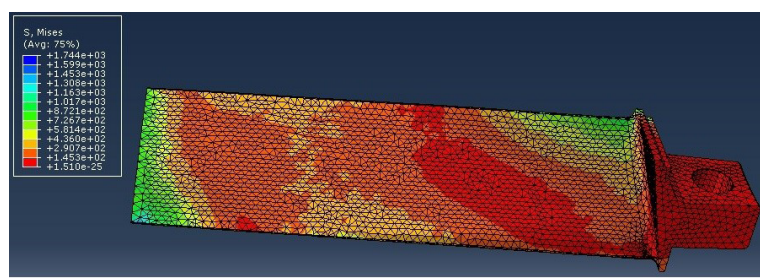

Fig. 7. The calculated residual stresses by the Von Mises yield criterion due to machining operation of turbine blade in MPa unit

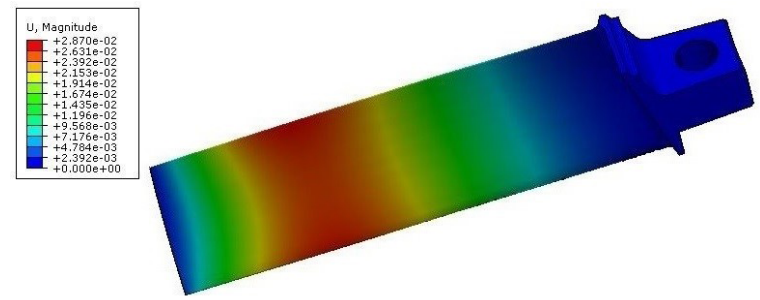

Fig. 8. The calculated deflection error of machined turbine blade 
The calculated deflection error of the machined turbine blade by using the FEM method is presented in Fig. 8.

Residual stresses of the machined blade are measured by using an X-ray diffraction method. In order to obtain the residual stress in the machined turbine blades, two-circle Bragg BrentanoDiffractometer of the type Philips X'PERT MPD is used by $\mathrm{Cr} k_{\alpha}$ radiation with $35 \mathrm{kV}$ and $35 \mathrm{~mA}$. The $\sin 2 \psi$ method is the most widely used methodology for stress assessment. Several XRD measurements are performed by considering the different tilts angle of $\psi$. In this experiment, the tilting angles are set at $0^{\circ}, 13.8^{\circ}$, $18.7^{\circ}, 24.3^{\circ}, 29.4^{\circ}, 32.2^{\circ}, 34.8^{\circ}, 36.5^{\circ}$, and $40.4^{\circ}$. The inter-planar spacing or two-theta peak is calculated in order to obtain a plot or a curve for the measured data. As a result, the stress can be determined using the obtained plot by measuring the line gradient and with simple knowledge of the material's elastic properties. In order to measure the residual stress in the machined turbine blades, the X-ray diffraction method is used, as shown in Fig. 9.

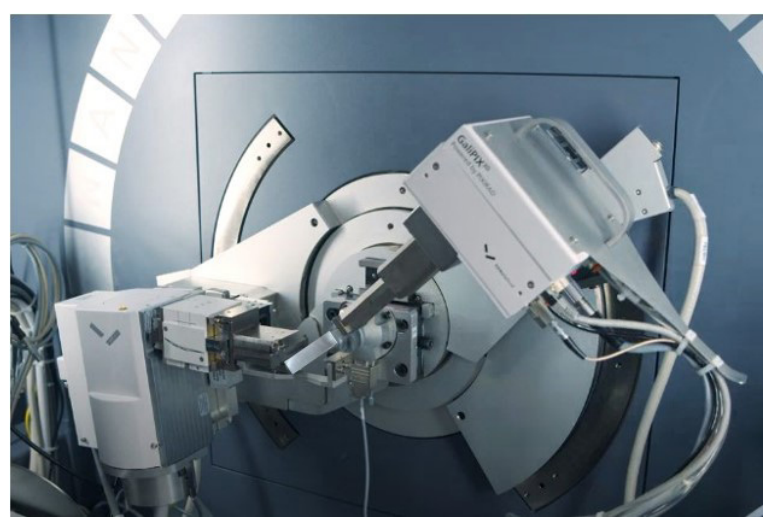

Fig. 9. The X-ray diffraction method to measure the residual stress of machined turbine blade

The residual stresses in the depth of machined blade are measured and presented in the Fig. 10.

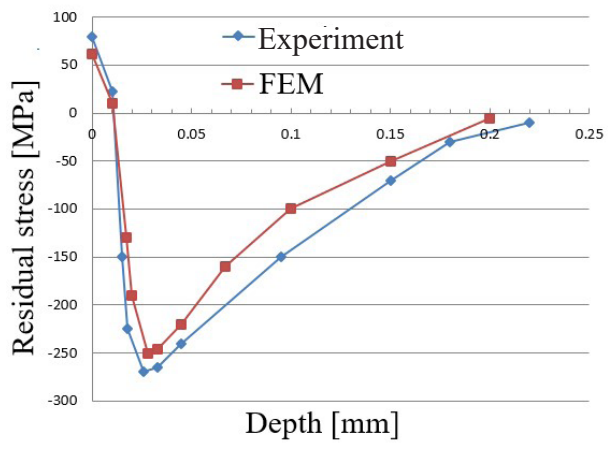

Fig. 10. Measured residual stress in depth of produced blade
A $90.4 \%$ compatibility is obtained in the comparison of the results of the experimental test and FEM simulation. Optimized machining parameters are calculated using the optimization techniques developed in the study based on the genetic algorithm. To measure the cutting forces in the machining operation, the Kistler dynamometer is used. To provide input data for the optimization process, the measured cutting forces and cutting temperature, cutting condition and cutting tool geometry are entered in the optimization algorithm. In the optimization process, a population size of 28 is selected with the iterated for 228 generations. Also, the probability of crossover of 0.85 and mutation of 0.001 are selected. As a result, the feed rate $87 \mathrm{~mm} / \mathrm{min}$, radial feed $a_{e} 0.2$ $\mathrm{mm}$ and axial feed $a_{p} 12 \mathrm{~mm}$ and the spindle speed $1269 \mathrm{rpm}$ are obtained. Measured residual stress in the depth of machined blade using optimized machining parameters is shown in Fig. 11.

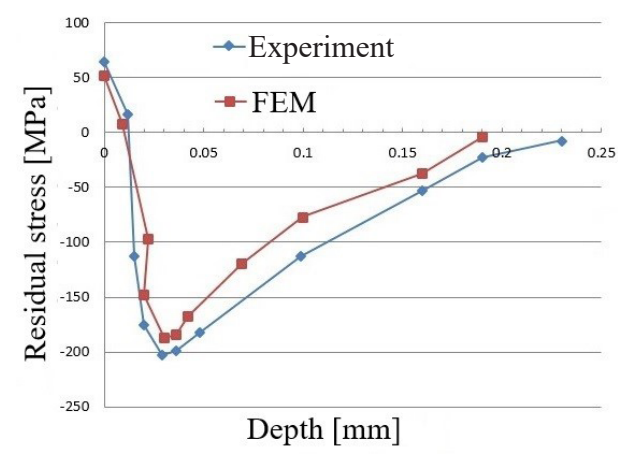

Fig. 11. Measured residual stress in depth of machined blade using optimized machining parameters

In order to measure the deflection error in the machined turbine blades, the CMM machine is used. The used probe in the error measuring is the Renishaw RSH 250 probe while its repeated accuracy is $1 \mu \mathrm{m}$ in touching directions. The sweep scan method is used to obtain the surface condition of the machined blade.

A NURBS surface "patch" is generated for each of the sweep scans in order to obtain the deflection error in the machined turbine blades. Then, to obtain the deflection error, sections are taken along the generated surfaces at any required height. The amount of error between the CAD model of turbine blade and fitted NURBS surfaces from the measured data of the CMM machine are calculated in each section of generated surface as the deflection error of machined turbine blade.

The process of surface generation and deflection error calculation due to cutting forces and cutting 
temperature for the machined blade are shown in Fig. 12.

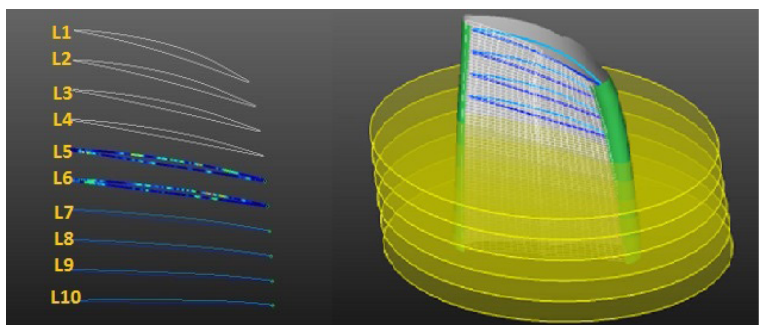

Fig. 12. The deflection error calculation from the CAD model of turbine blade and generated NURBS surfaces of machined turbine blades

As a result, the measured and predicted deflection errors in the machined turbine blade without and with the optimized machining parameters for the L7 line in Fig. 12 is presented in Fig. 13.

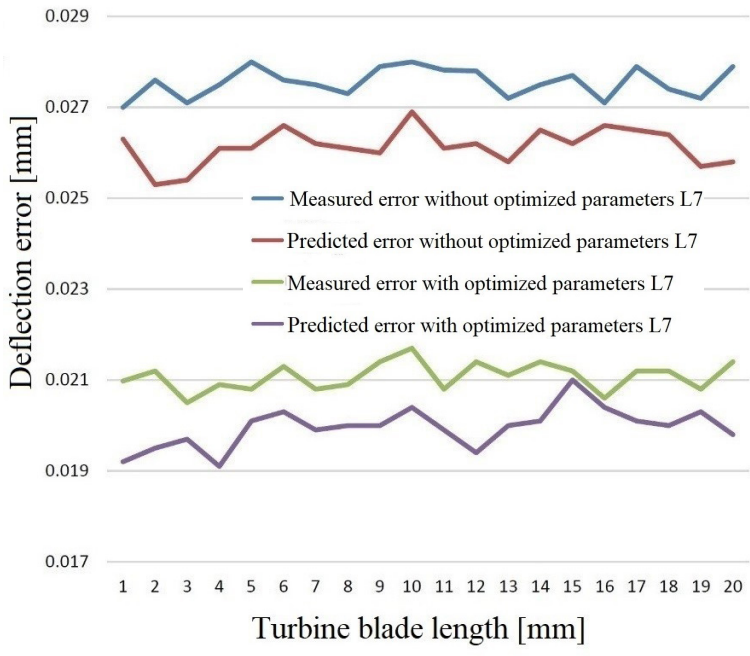

Fig. 13. The measured and predicted deflection errors in the machined turbine blade without and with optimized machining parameters for the $L 7$ line in the Fig. 12

The predicted deflection error due to the cutting forces and cutting temperatures without optimized machining parameters for the L7 line in Fig. 12 is presented in Fig. 14.

The optimized machining parameters can decrease the unnecessary cutting forces and the cutting temperature in the machining operation. Therefore, a reduction in the residual stress of produced blades using optimized machining parameters can be achieved, which can increase accuracy as well as reliability of machined turbine blades. Moreover, the deflection error due to machining forces and cutting temperature is minimized to increase the accuracy of machined turbine blades.

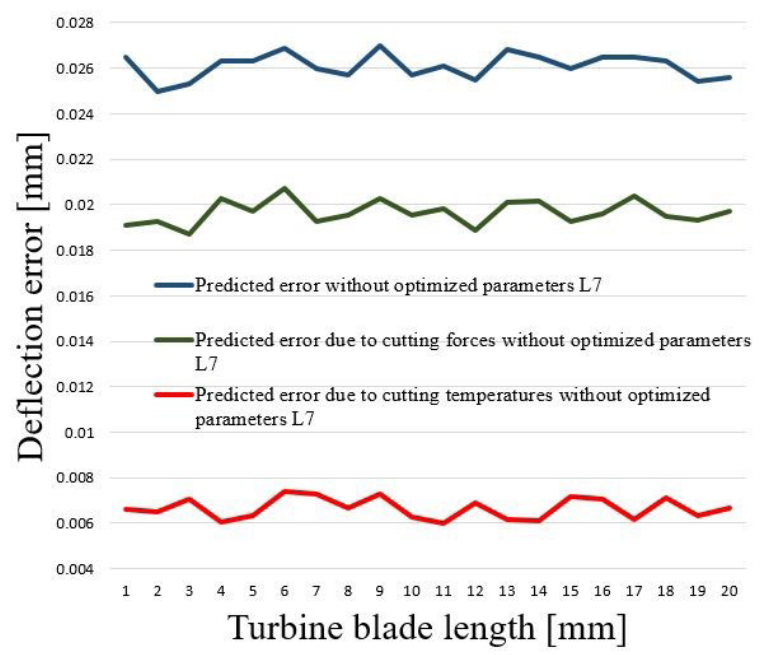

Fig. 14. The predicted deflection error due to the cutting forces and cutting temperatures without optimized machining parameters for the $L 7$ line in the Fig. 12

\section{CONCLUSIONS}

To predict and minimize residual stress and deflection error in a five-axis turbine blade milling operations, a virtual machining system is developed in the study. The system can calculate the cutting forces and cutting temperature at each position of the cutting tool along machining paths with regard to the parameters of machining operations, geometries, and material properties of cutting tools as well as workpieces. Then, FEA is used to obtain residual stress and deflection error of the turbine blades in machining operations. The real turbine blades are produced and experimentally tested using a five-axis CNC milling machine tool in order to validate the developed system in the study. Then, the residual stress in the machined turbine blades are measured using X-ray diffraction machines. To measure the deflection error in the machined blades, the CMM machine is used. Finally, the obtained results from the virtual machining system and experimental tests are compared to present the rate of compatibility in the developed system. Therefore, a $90.4 \%$ and $94.3 \%$ compatibility are obtained in comparison to the experimental and virtual machining system results for the residual stress and deflection error, respectively.

To minimize the residual stress and deflection error in machining operation, optimized machining parameters using the genetic algorithm is obtained. As a result, $24.2 \%$ and $23.9 \%$ reductions in residual stress can be obtained in the real machined turbine blade and virtual machining system results. respectively. Moreover, $26.3 \%$ and $24.1 \%$ reductions 
in the deflection error of real and virtual machining systems results are respectively measured by using the optimized machining parameters in machining operations.

The accuracy and the reliability of machined turbine blades can be increased by using the application of the virtual machining system in the minimization of residual stress and deflection error due to machining operations. Furthermore, the amount of the deflection errors due to cutting forces and cutting temperatures can be accurately predicted in virtual environments using the FEM analysis. The system developed in this study can be used in the machining operations of free-form surfaces in aircraft airfoils by using the five-axis CNC machine tools in order to decrease the residual stress of machined parts. These are the concepts of future research works for the authors.

\section{REFERENCES}

[1] Wimmer, S., Zaeh, M. (2018). The prediction of surface error characteristics in the peripheral milling of thin-walled structures. Journal of Manufacturing and Materials Processing, vol. 2, no. 1, art. ID 13, D0l:10.3390/jmmp2010013.

[2] Grossi, N., Scippa, A., Venturini, G., Campatelli, G. (2020). Process parameters optimization of thin-wall machining for wire arc additive manufactured parts. Applied Sciences, vol. 10, no. 21, art ID. 7575, DOl:10.3390/app10217575.

[3] Ratchev, S., Liu, S., Becker, A.A. (2005). Error compensation strategy in milling flexible thin-wall parts. Journal of Materials Processing Technology, vol. 162-163, p. 673-681, DOl:10.1016/j.jmatprotec.2005.02.192.

[4] Grossi, N., Scippa, A., Croppi, L., Morelli, L., Campatelli, G. (2019). Adaptive toolpath for 3-axis milling of thin walled parts. MM Science Journal, no. 04, p. 3378-3385, D0l:10.17973/ MMSJ.2019_11_2019096.

[5] Scippa, A., Grossi, N., Campatelli, G. (2014). FEM based cutting velocity selection for thin walled part machining. Procedia CIRP, vol. 14, p. 287-292, D0l:10.1016/j.procir.2014.03.023.

[6] Bolsunovskiy, S., Vermel, V., Gubanov, G., Kacharava, I., Kudryashov, A. (2016). Thin-walled part machining process parameters optimization based on finite-element modeling of workpiece vibrations. Procedia CIRP, vol. 8, p. 276-280, D0l:10.1016/j.procir.2013.06.102.

[7] Jiang, X., Li, B., Wang, L., Wang, Z., Li, H. (2016). An approach to evaluate the effect of cutting force and temperature on the residual stress generation during milling. The International Journal of Advanced Manufacturing Technology, vol. 87, p. 2305-2317, DOl:10.1007/s00170-016-8605-5.

[8] Masmiati, N., Sarhan, A.A., Hassan, M.A.N., Hamdi, M. (2016). Optimization of cutting conditions for minimum residual stress, cutting force and surface roughness in end milling of S50C medium carbon steel. Measurement, vol. 86, p. 253265, DOI:10.1016/j.measurement.2016.02.049.
[9] Mohammadpour, M., Razfar, M.R., Saffar, R.J. (2010). Numerical investigating the effect of machining parameters on residual stresses in orthogonal cutting. Simulation Modelling Practice and Theory, vol. 18, no. 3, p. 378-389, Dol:10.1016/j. simpat.2009.12.004.

[10] Zhang, X., Wu, H. (2018). Effect of tool angle on cutting force and residual stress in the oblique cutting of TC21 alloy. The International Journal of Advanced Manufacturing Technology, vol. 98, p. 791-797, DOl:10.1007/s00170-018-2324-z.

[11] Lin, K., Wang, W., Jiang, R., Xiong, Y. (2019). Effect of tool nose radius and tool wear on residual stresses distribution while turning in situ TiB2/7050 Al metal matrix composites. The International Journal of Advanced Manufacturing Technology, vol. 100, p. 143-151, Dol:10.1007/s00170-018-2742-y.

[12] Yang, D., Xiao, X., Liang, X. (2019). Analytical modeling of residual stress in orthogonal cutting considering tool edge radius effect. The International Journal of Advanced Manufacturing Technology, vol. 103, p. 2965-2976, DOI:10.1007/s00170-019-03744-9.

[13] Nasr, M.N.A., Ng, E.-G., Elbestawi, M.A. (2007). Modelling the effects of tool-edge radius on residual stresses when orthogonal cutting AISI 316L. International Journal of Machine Tools and Manufacture, vol. 47, no. 2, p. 401-411, Dol:10.1016/j.jimachtools.2006.03.004.

[14] Arunachalam, R.M., Mannan, M.A., Spowage, A.C. (2004). Residual stress and surface roughness when facing age hardened Inconel 718 with CBN and ceramic cutting tools. International Journal of Machine Tools and Manufacture, vol. 44, no. 9, p. 879-887, D0l:10.1016/j.jijmachtools.2004.02.016.

[15] Sharman, A.R.C., Hughes, J.I., Ridgway, K. (2015). The effect of tool nose radius on surface integrity and residual stresses when turning Inconel $718^{\mathrm{T}}$. Journal of Materials Processing Technology, vol. 216, p. 123-132, Dol:10.1016/j. jmatprotec.2014.09.002.

[16] Yan, Q., Luo, M., Tang, K. (2018). Multi-axis variable depthof-cut machining of thin-walled workpieces based on the workpiece deflection constraint. Computer-Aided Design, vol. 100, p. 14-29, DOI:10.1016/j.cad.2018.02.007.

[17] Huang, N., Bi, Q., Wang, Y., Sun, C. (2014). 5-Axis adaptive flank milling of flexible thin-walled parts based on the onmachine measurement. International Journal of Machine Tools and Manufacture, vol. 84, p. 1-8, D0l:10.1016/j. ijmachtools.2014.04.004.

[18] Shakya, P., Sunny, M.R., Maiti, D.K. (2020). Time domain flutter analysis of bend-twist coupled large composite wind turbine blades: a parametric study. Mechanics Based Design of Structures and Machines, p. 1-23, DOI:10.1080/15397734 .2020.1824796.

[19] Luo, Z., Wang, Y., Zhai, J., Zhu, Y., Wang, D. (2019). Prediction of vibration characteristics of blisks using similitude models. Mechanics Based Design of Structures and Machines, vol. 47, no. 2, p. 121-135, Dol:10.1080/15397734.2018.1481427.

[20] Soori, M., Arezoo, B., Habibi, M. (2017). Accuracy analysis of tool deflection error modelling in prediction of milled surfaces by a virtual machining system. International Journal of Computer Applications in Technology, vol. 55, no. 4, p. 308321, DOI:10.1504/ijcat.2017.10006843. 
[21] Soori, M., Arezoo, B., Habibi, M. (2014). Virtual machining considering dimensional, geometrical and tool deflection errors in three-axis CNC milling machines. Journal of Manufacturing Systems, vol. 33, no. 4, p. 498-507, D0I:10.1016/j.jmsy.2014.04.007.

[22] Soori, M., Arezoo, B., Habibi, M. (2013). Dimensional and geometrical errors of three-axis CNC milling machines in a virtual machining system. Computer-Aided Design, vol. 45, no. 11, p. 1306-1313, D0I:10.1016/j.cad.2013.06.002.

[23] Soori, M., Arezoo, B. (2021). Virtual Machining Systems for CNC Milling and Turning Machine Tools: A Review. International Journal of Engineering and Future Technology, vol. 18, no. 1, p. 56-104.

[24] Soori, M., Arezoo, B., Habibi, M. (2016). Tool deflection error of three-axis computer numerical control milling machines, monitoring and minimizing by a virtual machining system. Journal of Manufacturing Science and Engineering, vol. 138, no. 8, art. ID. 081005, D0I:10.1115/1.4032393.

[25] Soori, M., Asamel, M., Solyali, D. (2020). Recent development in friction stir welding process: A review. SAE International Journal of Materials and Manufacturing, vol. 14, no. 1, p. 6380, D0I:10.4271/05-14-01-0006.

[26] Nasir, T., Kalaf, O., Asmael, M. (2021). Effect of rotational speed, and dwell time on the mechanical properties and microstructure of dissimilar AA5754 and AA7075-T651 aluminum sheet alloys by friction stir spot welding. Materials Science. Early Access, D0I: 10.5755/j02.ms.26860.
[27] Zhang, X., Zhang, J., Pang, B., Zhao, W. (2016). An accurate prediction method of cutting forces in 5-axis flank milling of sculptured surface. International Journal of Machine Tools and Manufacture, vol. 104, p. 26-36, D0l:10.1016/j. ijmachtools.2015.12.003.

[28] Mia, M., Dhar, N.R., (2016). Response surface and neural network based predictive models of cutting temperature in hard turning. Journal of Advanced Research, vol. 7, no. 6, p. 1035-1044, D0l:10.1016/j.jare.2016.05.004.

[29] Shaw, M.C. (2005). Metal Cutting Principles. $2^{\text {nd }}$ ed., Oxford University Press, Oxford.

[30] Santos, M.C., Machado, A.R., Barrozo, M.A. (2018). Temperature in machining of aluminum alloys. in: temperature sensing. IntechOpen, DOI:10.5772/intechopen.75943.

[31] Wan, M., Zhang, W.H., Qin, G., Wang, Z.P. (2008). Strategies for error prediction and error control in peripheral milling of thin-walled workpiece. International Journal of Machine Tools and Manufacture, vol. 48, no. 12-13, p. 1366-1374, DOI:10.1016/j.ijmachtools.2008.05.005.

[32] Palanisamy, P., Rajendran, I., Shanmugasundaram, S. (2007). Optimization of machining parameters using genetic algorithm and experimental validation for end-milling operations. The International Journal of Advanced Manufacturing Technology, vol. 32, p. 644-655, D0l:10.1007/s00170-005-0384-3.

[33] Tolouei-Rad, M., Bidhendi, I. (1997). On the optimization of machining parameters for milling operations. International Journal of Machine Tools and Manufacture, vol. 37, no. 1, p. 1-16, DOl:10.1016/S0890-6955(96)00044-2. 